\title{
Preparation and performance of insect virus microcapsules
}

\author{
Meng Luo ${ }^{1,2}$, Dandan Zhu ${ }^{1,2}$, Juntao Lin ${ }^{1,2}$, Xinhua Zhou ${ }^{1,2}$, Changge Zheng ${ }^{3}$ and Xia Pu ${ }^{1,2^{*}}$
}

\begin{abstract}
Background: Biological pesticides, especially baculovirus, often lose their activity under the influence of external light, temperature, and other changes. This limited the application of them. The present study was aimed to prolong the biological activity and ensure the efficacy of a biological pesticide using microencapsulation technology.

Results: In this study, gelatin/carboxymethylcellulose (CMC)-Spodoptera litura nucleopolyhedrovirus microcapsules were prepared. The morphological characteristics, apparent morphology, embedding rate, virus loading, particle size, laboratory virulence, and UV resistance of the microencapsulated virus, were tested. The best conditions for preparing gelatin /CMC-S. litura nucleopolyhedrovirus microcapsules include the gelatin/CMC ratio of 9:1, wall material concentration of 1\%, core material/wall ration ratio of 1:2, re-condensation $\mathrm{pH}$ of 4.67 , and curing time of 1 h. The prepared microcapsules of $S$. litura nucleopolyhedrovirus exhibited a good external appearance and spherical shapes with an average particle size of $13 \mu \mathrm{m}$, an embedding rate of $62.53 \%$, and a drug loading of $43.87 \%$. The virulence test showed that the microencapsulated virus lost by 2.21 times of its initial activity than the untreated virus. After being treated with field exposure, the gelatin/CMC shell of the microcapsule can better protect the virus in the wild environment.

Conclusion: Microencapsulation improves the tolerance of $S$. litura nuclear polyhedrosis virus to ultraviolet radiation. These results will provide ideas for the research of stable and efficient baculovirus preparations and further promote the application and promotion of environmental friendly biological pesticides.
\end{abstract}

Keywords: Nucleopolyhedrovirus, Microcapsules, UV resistance

\section{Background}

China is the largest producer and consumer of pesticides. Safety, efficacy, and environmental compatibility are the major concerns for pesticides (Xing et al., 2019). Excessive use of pesticides has led to a drug resistance among insect populations (Balabanidou et al., 2018). Pesticide residues in agricultural products eventually lead to environmental pollution and ecological imbalance (Bilal et al., 2019).

\footnotetext{
*Correspondence: puxia15@163.com

${ }^{1}$ College of Chemistry and Chemical Engineering, Zhongkai University of

Agriculture and Engineering, Guangzhou 510225, China

${ }^{2}$ Key Laboratory of Agricultural Green Fine Chemicals of Guangdong Higher

Education Institution, Guangzhou 510225, China

Full list of author information is available at the end of the article
}

Baculovirus, as a microbial insecticide, can spread horizontally and vertically in pest populations (Cory et al., 2015) and has high pathogenicity to insect species (Simon et al., 2004). It has received considerable attention to its characteristics such as strong sustainability, low resistance to pests, harmless to vertebrates, and friendly to the environment. Despite the advantages of using baculovirus, a major limitation of the virus is the need for frequent reapplication under field situations. Exposure to ultraviolet solar radiation (UVB, 280-320 $\mathrm{nm})$ is the most critical factor limiting the persistence of entomopathogenic viruses (Villamizar et al., 2009). Consequently, the formulations that encapsulate viral particles have been a preferred delivery system to minimize activity losses due to solar radiation (Tamez et al., 2002). 
Arthurs et al. (2006) spray-dried lignin-encapsulated formulations of $\mathrm{CpGV}$ which provided protection from UV radiation. However, the lignin shell of the prepared lignin microcapsules will dissolve in an aqueous solution within hours. It loses the significance of keeping a protective UV coating on the virus after spray application. Camacho et al. (2015) sprayed drying Eudragit ${ }^{\circ}$ S100 as a polymer coating to protect viral particles of UVinactivation. Due to the emulsification method, the pollution of a large amount of oil phase during the preparation process and the complicated impurity removal process make the microcapsule process cost too high (Yan et al., 2020).

Herein, the microcapsules were prepared by following a complex coacervation method and utilizing natural polymer gelatin/gum Arabic as the wall material (Gomez et al., 2018). However, gum Arabic is expensive and has poor stability. Because of its low price and stable properties, carboxymethyl cellulose was used as a substitute for gum Arabic. The negatively charged carboxymethyl cellulose can agglomerate with positively charged gelatin below the isoelectric point to yield microcapsules (Duhoranimana et al., 2018). Aldehydes are the most commonly used curing agent for the composite coacervation method. Unlike previous studies, environment-friendly tea polyphenols as the curing agent was used. The o-phenol groups in polyphenol are oxidized to o-benzoquinone to form a co-product with secondary protein amines. The characteristic covalent bond solidifies the capsule wall of the microcapsule, making the capsule wall denser and stronger. Using gelatin/sodium carboxymethylcellulose (CMC) as the wall material, tea polyphenols as the curing agent, and S. litura nucleopolyhedrovirus as the core embedding material, the gelatin/carboxymethylcellulose (CMC)-S. litura nucleopolyhedrovirus microcapsules were prepared, and their morphology, particle size, drug loading, and embedding rate were analyzed to determine the optimal conditions for preparing the gelatin/CMC wall materials. By measuring the activity of the virus and comparing the non-embedded, microencapsulated viruses, the factors affect the activity of the virus. The UV tolerance of unencapsulated virus and microencapsulated virus was investigated after outdoor sunlight irradiation, providing ideas for the research of stable and efficient baculovirus preparations, so as to further promote the application and promotion of environmental friendly biological pesticides.

\section{Methods}

\section{Materials}

Type A gelatin (chemically pure or CP), sodium hydroxide $(\mathrm{NaOH})$ (analytically pure or AP), and carboxymethyl cellulose (AP) were purchased from Shanghai Aladdin Reagent Company. Glacial acetic acid (AP) was obtained from Tianjin Chemical Reagent Factory. Tea polyphenols $(\mathrm{CP})$ were purchased from Hefei Basifu Biotechnology Co., Ltd.

Electronic Analytical Balance, CPA225D, Sartorius AG, Germany. Ultra-Pure Water Preparation System, Ulupure, Sichuan Ultra-Pure Technology Guangdong Branch. Collector Constant Temperature Heating Magnetic Stirrer, DF-101S, Gongyi Yuhua Instrument Co., Ltd. Scanning Electron Microscope, S4800, Hitachi Corporation, Japan. Zeta Particle Size Instrument, 90Plus, Bruker Analytical Instruments, Germany. Freeze Dryer, Alpha 1-2 LD Plus, Christ, Germany. Optical Microscope, CX-41X, Olympus, Japan. High Speed Cryogenic Centrifuge, GI54DS, Ebender China Co. Ltd. UV Spectrophotometer, T6 New Century, Beijing Spectroscopy Instrument Co., Ltd.

\section{Insect rearing and virus}

Insects and S. litura nucleopolyhedrovirus were obtained from Guangzhou Biological Control Station. Larvae were kept individually in half-ounce plastic containers with a fragment of surface contamination of diet. Inoculated larvae were incubated at $27 \pm 1^{\circ} \mathrm{C}$ and fed with artificial diet until dying due to the infection. Dead larvae were collected, ground in distilled sterile water, and homogenized. The virus liquid was obtained by differential centrifugal method, and then the virus powder was freezedried.

\section{Preparation of viral microcapsules}

Gelatin and CMC were weighed, wherein the mass ratios of gelatin/CMC were 7:1, 9:1, and 11:1. Deionized water was added, and the solution was stirred at $35{ }^{\circ} \mathrm{C}$ until it appeared colorless and transparent. Accurately, $100 \mathrm{ml}$ of the mixed solution was taken, $\mathrm{m}_{0} \mathrm{~g}$ of virus dry powder was added, then it was dispersed at $300 \mathrm{r} / \mathrm{min}$ for $5 \mathrm{~min}$ at $25^{\circ} \mathrm{C}$. Then, a $10 \%$ acetic acid solution was added drop by drop, while using an optical microscope to observe the encapsulation of the polymer in the solution. When capsules appeared, the addition of the acetic acid solution was stopped, and the reaction was continued for $10 \mathrm{~min}$. Tea polyphenol was added (as curing agent) for curing for several hours. The microcapsule suspension was washed with slow filter paper and clean water, and the wet capsules were obtained. The wet capsules were re-suspended and centrifuged at $1000 \mathrm{r} / \mathrm{min}$ for $10 \mathrm{~min}$, the supernatant was discarded, and the precipitate was freeze-dried to obtain solid microcapsules (yield $-\mathrm{m}_{1} \mathrm{~g}$ ).

\section{Determination of absorbance of composite condensate}

Gelatin/CMC solution was prepared at a concentration of $0.1 \%(\mathrm{w} / \mathrm{v})$. The solution was placed in a $35{ }^{\circ} \mathrm{C}$ water bath, the rotation speed was adjusted to $300 \mathrm{r} / \mathrm{min}, 10 \%$ acetic acid was prepared to adjust the $\mathrm{pH}$ value of the solution system, samples were withdrawn at different $\mathrm{pH}$ 
values, and then the absorbance at $600 \mathrm{~nm}$ was measured using an ultraviolet spectrophotometer.

\section{Measurement of zeta potential}

Gelatin and CMC solution at a concentration of $0.01 \%$ $(\mathrm{w} / \mathrm{v})$ was prepared and adjusted to the desired $\mathrm{pH}$ value. Then, $2 \mathrm{ml}$ of the solution was withdrawn each time, and a particle size analyzer (90Plus, Bruker Analytical Instruments, Germany) was used to determine the zeta potential of the solution.

\section{Calculation of composite condensate yield}

Gelatin/CMC solution at a concentration of $0.1 \%(\mathrm{w} /$ v) was prepared, and the rotational speed was adjusted to $300 \mathrm{r} / \min$ in a $35{ }^{\circ} \mathrm{C}$ aqueous solution. Then, a $10 \%$ acetic acid was prepared to adjust the $\mathrm{pH}$ value of the solution system, until the system undergoes complex coacervation. When the condensate reaction was continued for $10 \mathrm{~min}$, the system was cooled below $15{ }^{\circ} \mathrm{C}$ with ice water. The reaction system was refrigerated and allowed to stand overnight. After centrifuging at a low speed, the sediment was collected from the tube and placed in a freeze dryer for $4 \mathrm{~h}$. The weight was recorded, and the yield was then calculated.

\section{Purification and separation of S. litura nucleopolyhedrovirus}

Differential centrifugation was used, a suspension was prepared with the wet powder of the virus, then it was centrifuged at $1000 \mathrm{r} / \mathrm{min}$ for $5 \mathrm{~min}$, and the precipitate was discarded. The supernatant was centrifuged at 3500 $\mathrm{r} / \mathrm{min}$ for $20 \mathrm{~min}$, then the precipitate was re-suspended and centrifuged at $3500 \mathrm{r} / \mathrm{min}$ for $20 \mathrm{~min}$. Differential centrifugation was repeated several times until the polyhedron suspension showed uniformly light gray. The separated virus was freeze-dried to make a dry virus powder. Then, $0.1 \mathrm{~g} / \mathrm{ml}$ virus solution was prepared, and $1 \mathrm{ml}$ was diluted to $100 \mathrm{ml}$. Blood cell counting method was used to calculate the virus concentration $\mathrm{P}_{0}$ (PIB/ $\mathrm{ml}$ ), wherein $\mathrm{P}_{0}=\frac{\mathrm{A}}{80} \times 4 \times 10^{6} \times 100$ ( $\mathrm{A}$ is the number of virus particles in the 5 middle grids or 80 small grids, 100 is the dilution factor).

\section{Determination of drug loading and embedding rate}

The filtrate from microcapsule preparation was reserved, after shaking well, placed in a hemocytometer; the number was counted under a microscope; and the amount of virus in the filtrate was calculated as $\mathrm{p}_{1}$ (PIB).

The calculation formula of microcapsule drug loading:

$$
\mathrm{L}(\%)=\frac{m_{0}-\left(\frac{P_{1}}{P_{0}}\right)}{m_{1}} \times 100 \%
$$

The embedding rate calculation formula:

$$
\mathrm{EE}(\%)=\frac{m_{0}-\left(\frac{P_{1}}{P_{0}}\right)}{m_{0}} \times 100 \%
$$

\section{Observation of microcapsule morphology}

During the formation of microcapsules, a drop of reaction suspension was withdrawn and placed on a glass slide. Using an optical microscope, the appropriate magnification and aperture brightness were adjusted to observe the morphology of the microcapsules.

The microencapsulated viruses and purified polyhedron viruses were withdrawn and diluted with an appropriate amount of ultrapure water to prepare a suspension. The suspension was placed on a clean cover glass; it was dried naturally or dried under an infrared lamp. The distance between the infrared lamp and the sample slide was about $15-20 \mathrm{~cm}$. After baking for 5-10 min, gold was sprayed. Finally, the external morphologies of the microcapsules and polyhedrosis viruses were observed under a scanning electron microscope (EVO 18).

\section{Virulence assays}

The 3rd instar larvae were selected as test insects. The larvae were reared in plastic boxes with vent holes and 2 $\mathrm{ml}$ of each virus suspension after 10-fold concentration dilution was evenly applied, using a brush on the surface of the feed to surface contamination assays. After the surface was room temperature air dried, 3rd instar larvae were inoculated ( 20 individuals per box). Based on the drug loading calculation, a series of microencapsulated virus suspensions at the same concentration as the unembedded virus were prepared and diluted. The larvae in the control group were fed by the same amount of sterile water, and the experiment was repeated 3 times in each group. The temperature of the culture room was $25{ }^{\circ} \mathrm{C}$, and the light of that was maintained at 12L:12D. The death of the test insects was observed and recorded every day until all larvae died or pupated. After eating the surface of the feed, a clean feed was used for rearing. Count the deaths and calculate the cumulative mortality rate. LC $_{50}$ (Karber method) was calculated by SPSS software.

\section{Field exposure treatment}

Place the Petri dish coated with virus polyhedrons and microencapsulated virus dry powder on a platform without sunshade. As the UV intensity in Guangzhou was as 
high as $4000 \mu \mathrm{w} / \mathrm{cm}^{2}$ at noon at the maximum, the virus will be rapidly inactivated and cannot be sampled and stored in time, so choose field radiation experiments are conducted from 17:00 in the evening to 8:00 in the morning of the next day. Record the daily weather conditions (Table 1) different from the $0,2,4,6,8$, and $10 \mathrm{~d}$ time labels, parallel three times each, take them away, and store them in a refrigerator at $4{ }^{\circ} \mathrm{C}$ for testing.

\section{Biological test}

The viruses and microencapsulated viruses with field exposure treatment were prepared into suspensions with respective $7.75 \times 10^{6} \mathrm{PIB} / \mathrm{ml}$, and $1 \mathrm{ml}$ was taken on the artificial feed, and the surface was dried naturally. The temperature of the culture room was $25^{\circ} \mathrm{C}$, and the light of that was maintained at 12L:12D. Insert healthy 3 rd $S$. litura larvae in the insect box, and receive 20 larvae per treatment, repeat 3 times, and set distilled water as a blank control in each experiment. After eating the surface feed, change the feed and continue feeding, observe the number of larval mortality rate per day, calculate the cumulative mortality, and correct the mortality.

\section{Statistical analysis}

All measurements were performed in triplicates. The results obtained were presented as means. Data were mapped by origin 9.1 software (OriginLab Inc., 2013). Log transformed virus test concentrations $(\mathrm{PIB} / \mathrm{ml})$ were regressed on cumulative mortality data adopting Probit analysis to estimate LC50 value at $95 \%$ confidence limits (Finney, 1971) using SPSS Base 24.0 software (SPSS Inc., 2016). Mortality in control group was included in the Probit analysis.

\section{Results}

\section{Analysis of gelatin/CMC complex coacervation}

The microscopic interaction between CMC and gelatin molecules generated the composite condensate. As the
$\mathrm{pH}$ value of the system solution was changed, the solution underwent macroscopic changes from transparent to turbidity then to precipitation, which was caused by the different colloidal states of the macromolecules in the process. Within a certain range, turbidity was proportional to absorbance, so the turbidity of the solution was expressed in terms of absorbance. Figure 1 shows the absorbance of the $\mathrm{CMC} /$ gelatin system changes with $\mathrm{pH}$ value. When the addition of the acetic acid solution was started, the system $\mathrm{pH}$ was nearly neutral. At this time-point, the electrostatic repulsions of CMC and gelatin molecules were strong, because both contained a large amount of negative charge. The turbidity value was close to 0 , and macroscopically, the solution appeared clear and transparent. When the volume of instilled acetic acid solution was increased, the $\mathrm{pH}$ value slowly decreased; also, the absolute value of the $\zeta$ potential of the gelatin molecules started to decrease, and the positive charge gradually increased. Thus, a small amount of soluble composite condensate was produced, and the turbidity of the system slightly increased, but the solution still appeared transparent macroscopically. Subsequently, the $\mathrm{pH}$ value was continued to decrease, and the turbidity of the system slowly increased. As the $\mathrm{pH}$ value was continuously reduced, after exceeding a certain threshold $\mathrm{pH}$, the turbidity increased rapidly, which indicated that the system underwent phase separation because the soluble composite condensate was produced before undergoing a structural rearrangement, which formed insoluble composite condensate (Jones et al., 2009). When the turbidity rose to the highest point, the $\mathrm{pH}$ was the maximum and the peak turbidity indicated that the electrostatic interaction between CMC and gelatin reached a peak. When the $\mathrm{pH}$ value was continued to decrease, the turbidity of the system decreased rapidly, this might be related to the insoluble composite condensate to form a composite condensate with poor fluidity and tight structure. After the system solution

Table 1 Daily weather conditions in the field exposure experiment

\begin{tabular}{|c|c|c|c|c|c|c|c|}
\hline \multirow[t]{2}{*}{ Date } & \multirow[t]{2}{*}{ Weather } & \multicolumn{3}{|c|}{ Temperature $\left({ }^{\circ} \mathrm{C}\right)$} & \multicolumn{3}{|c|}{ UV intensity $\left(\mu \mathrm{w} / \mathrm{cm}^{2}\right)$} \\
\hline & & $18 \mathrm{pm}$ & $22 \mathrm{pm}$ & $8 \mathrm{am}$ & $18 \mathrm{pm}$ & $22 \mathrm{pm}$ & $8 \mathrm{am}$ \\
\hline 20-7-2019 & Clear & 30 & 29 & 27 & 856 & 0 & 1135 \\
\hline $21-7-2019$ & Clear & 31 & 28 & 29 & 972 & 0 & 1097 \\
\hline $22-7-2019$ & Overcast & 27 & 26 & 26 & 358 & 1 & 465 \\
\hline 23-7-2019 & Clear & 32 & 27 & 29 & 736 & 0 & 861 \\
\hline 24-7-2019 & The light rain turned fine & 25 & 26 & 31 & 104 & 0 & 796 \\
\hline $25-7-2019$ & Clear & 29 & 27 & 30 & 785 & 0 & 1106 \\
\hline 26-7-2019 & Clear & 30 & 29 & 31 & 893 & 0 & 1283 \\
\hline 27-7-2019 & Sunny to overcast & 31 & 27 & 28 & 625 & 0 & 326 \\
\hline 28-7-2019 & Clear & 32 & 30 & 31 & 830 & 0 & 994 \\
\hline 29-7-2019 & Overcast to light rain & 28 & 25 & 25 & 264 & 0 & 97 \\
\hline
\end{tabular}




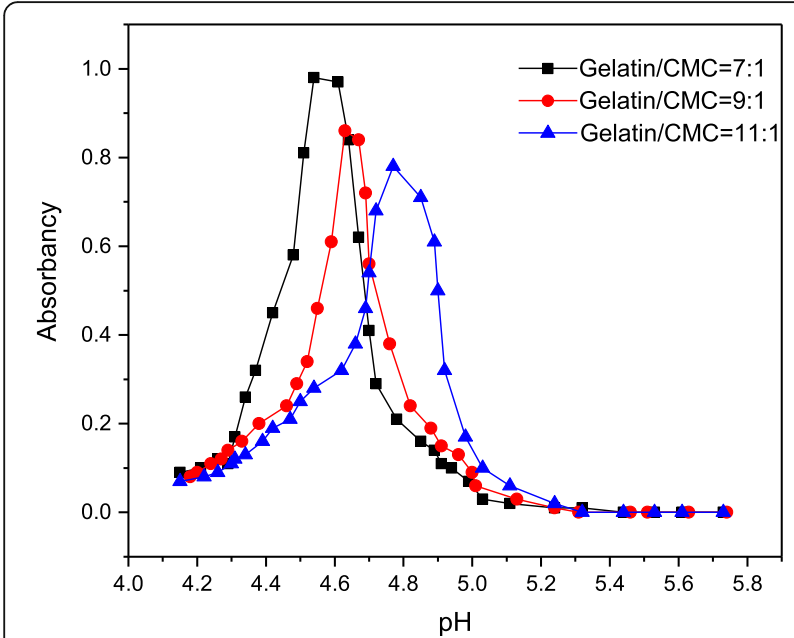

Fig. 1 Variation of absorbance of gelatin/CMC composite condensate with gelatin/CMC ratio and $\mathrm{pH}$

reached a certain $\mathrm{pH}$ value, the turbidity decreased slowly, because the aggregation of the protein caused a reduction of the decomposition tendency of the insoluble composite condensate (Serge et al., 2006). The resulting condensate was in a liquid state, which could be evenly dispersed in water. When the $\mathrm{pH}$ value was continuously decreased to a certain critical value, the flocculation and sedimentation trends of the condensate were obvious, which might be related to the mutual aggregation of the droplets of the condensate and the denser structure, resulting in a rapid decline in the absorbance value.

The yields of composite condensate with different ratios of gelatin/CMC at different $\mathrm{pH}$ values are shown in Fig. 2; when the ratio of gelatin/CMC was 11:1, the yield was the lowest, because the gelatin content was too high, and the content of CMC in the composite condensate

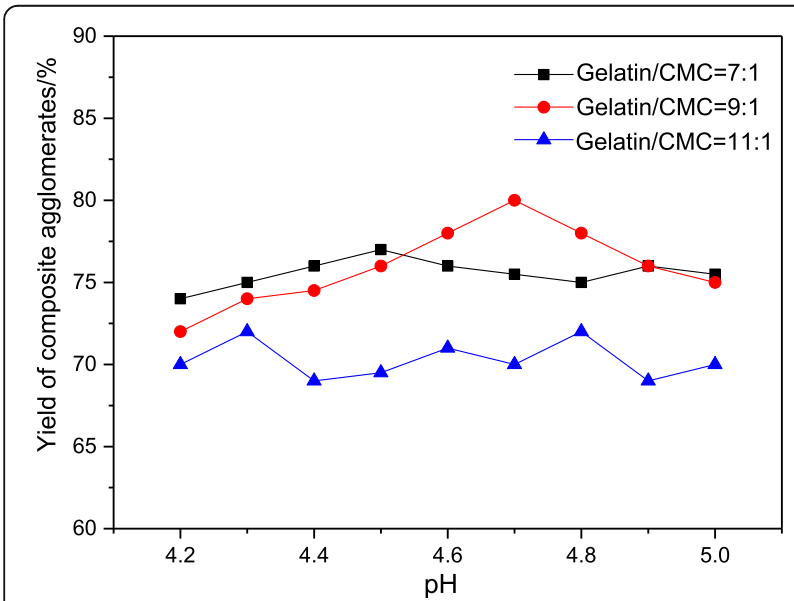

Fig. 2 The impact of gelatin/CMC ratio and $\mathrm{pH}$ value on the yields of composite condensates system was too low, which could not provide sufficient binding sites for the gelatin molecules in the system, then the yield of the composite condensate was reduced. The increase in the yield of the condensate indicated that the utilization rate of the wall material was increased, which was the basis for obtaining a better embedding effect of composite condensate microcapsule. The results of the condensate yield showed that for the three-different gelatin/CMC ratios, the yields of the composite condensate did not change much with the $\mathrm{pH}$ value, which also indicated that the change in the amount of the condensate did not cause the absorbance of the colloidal solution in the above figure. The change in absorbance reflected the change in the property of the condensate, caused by $\mathrm{pH}$ change.

\section{Determination of wall material ratio and $\mathrm{pH}$ value}

The $\mathrm{CMC} /$ gelatin ratio and $\mathrm{pH}$ value determine the properties of the composite condensate as a wall material because the type of charge and the amount of electricity charged by gelatin are greatly affected by the $\mathrm{pH}$ change, and the optimal $\mathrm{pH}$ value for the coagulation reaction will also be affected by the ratio of CMC and gelatin. Figures 4, 5, and 6 show the morphology of microcapsules prepared at different $\mathrm{pH}$ values with the gelatin/CMC ratio from 7:1 to 11:1. In these 3 ratios, as the $\mathrm{pH}$ value was changed from low to high, the morphology of the microcapsules was changed from dense super-polymer to single-core microcapsules and small flocculent aggregates.

Figure 3 shows the morphology of microcapsules at different $\mathrm{pH}$ values at a gelatin/CMC ratio of $7: 1$. At $\mathrm{pH}$ 4.64, spherical capsules can be produced with uniform particle size; however, the sparse distribution of microcapsule indicates a low yield. A small amount of condensate appeared at $\mathrm{pH} 4.78$ because the surface activity of $\mathrm{CMC}$ was low. The quantity of gelatin tape at this timepoint was low, and the electrostatic effect was not obvious. At $\mathrm{pH} 4.51$, the microcapsule spheres aggregated with each other to produce agglomerated superpolymer, and the spherical capsules disappeared.

Figure 4 shows the morphology of microcapsules at different $\mathrm{pH}$ values when gelatin/CMC was 9:1. The $\mathrm{pH}$ range for the formation of spherical microcapsules was 4.54 to 4.71 , and its particle size decreased while lowering the $\mathrm{pH}$ value. At $\mathrm{pH} 4.54$, the microcapsules were further concentrated and tended to agglomerate. At $\mathrm{pH}$ 4.76, the composite condensate formed small stripshaped agglomerates, because the viscosity of the system was too small, and the wall material did not sufficiently aggregate to form spherical microcapsules. Under this condition, the utilization rate of the microcapsule wall material was low, and it was difficult to be separated by 


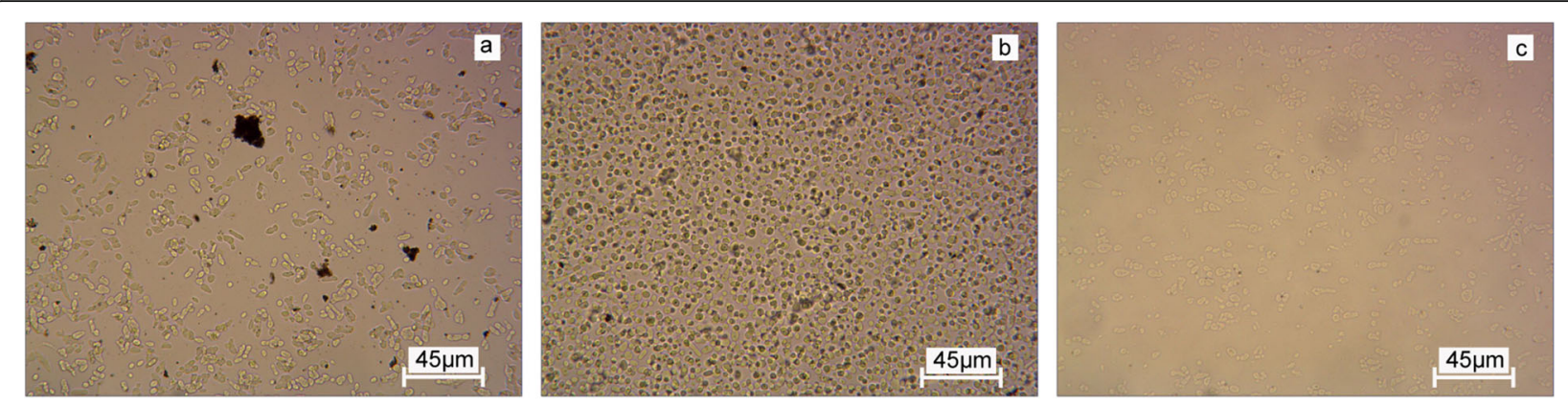

Fig. 3 The morphology of microcapsules at different $\mathrm{pH}$ values with the gelatin/ $\mathrm{CMC}$ ratio of 7:1. a $\mathrm{pH}=4.51, \mathrm{~b} \mathrm{pH}=4.64, \mathrm{c} \mathrm{pH}=4.78$. When the ratio of gelatin/CMC was 7:1, at pH 4.64, spherical capsules can be produced with uniform particle size; however, the sparse distribution of microcapsule indicates a low yield

filtration after curing, which affected the next research and specific application.

Figure 5 shows the morphology of microcapsules, prepared at different $\mathrm{pH}$ values with a gelatin/CMC ratio of 11:1. The $\mathrm{pH}$ range of microcapsules for pellet formation was between 4.69 and 4.74, which was narrower than the first 2 ratios, probably because when the ratio of gelatin/CMC was 11:1, the optimal $\mathrm{pH}$ value of the prepared microcapsules was close to the isoelectric point of gelatin. At this time-point, the positive charge on the gelatin molecule was small, and it was difficult to form a dense combination with the negatively charged CMC. Besides, the increase in the proportion of gelatin in the system would increase the number of gelatin molecules attached to a single $\mathrm{CMC}$ molecule in the formed condensate. Due to the increased steric hindrance, the condensate would become unstable.

Figures 3, 4, and 5 show that, as the ratio of gelatin/ $\mathrm{CMC}$ increases from 7:1 to $11: 1$, the $\mathrm{pH}$ value, required for a better shape of the microcapsule, gradually increased and the optimal $\mathrm{pH}$ value for preparing microcapsule increased with increase in the ratio of gelatin/ CMC. The optimal $\mathrm{pH}$ value of the condensation reaction would change, when the ratio of $\mathrm{CMC}$ to gelatin was changed, because when the gelatin/CMC ratio was changed, the amount of positive charge in the gelatin molecules could neutralize the negative charge of the $\mathrm{CMC}$, and the $\mathrm{pH}$ value at which gelatin molecule carried the positive charge would change accordingly.

The above results suggest that when the ratio of CMC and gelatin is fixed, the morphology and particle size of the composite condensate microcapsules influence $\mathrm{pH}$ change. The $\mathrm{pH}$ point at the maximum yield of the composite condensate decreased as the protein/polysaccharide ratio was decreased. Compared to gelatin/acacia system, gelatin/CMC system microcapsules were more sensitive to $\mathrm{pH}$ changes, the morphology and particle size of gelatin/ gum Arabic microcapsules changed significantly, when the $\mathrm{pH}$ change was above 0.3 (Sarika et al., 2015), probably because the two colloids carried opposite charges, and the electrostatic force between them drove the complex coacervation. The highest was the proportion of gelatin in the solution system, the greatest was the influence

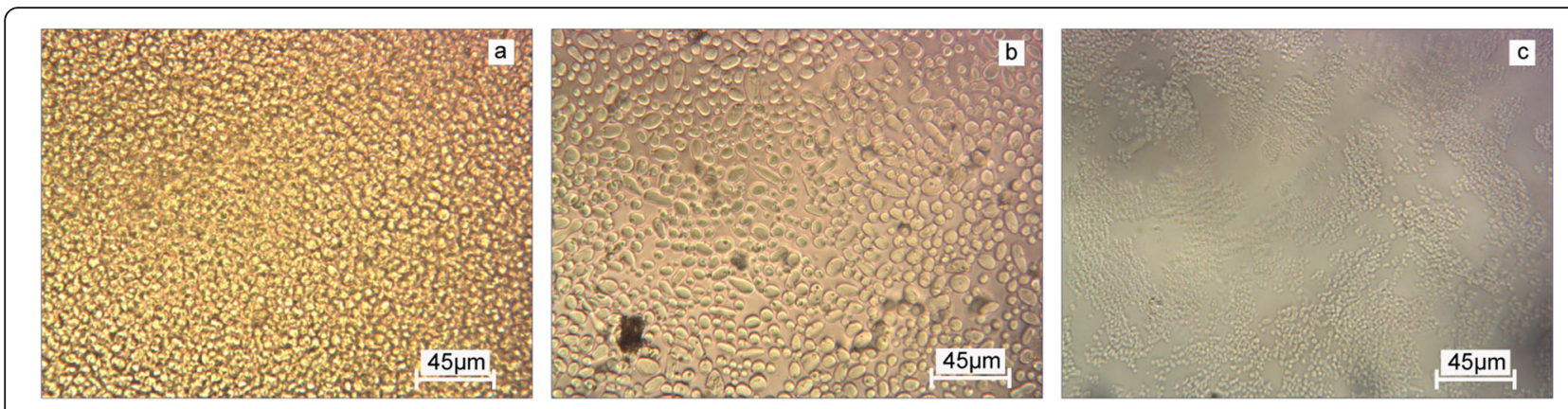

Fig. 4 The morphology of microcapsules at different $\mathrm{pH}$ values with the gelatin/ $\mathrm{CMC}$ ratio of 9:1. a $\mathrm{pH}=4.54, \mathrm{~b} \mathrm{pH}=4.71, \mathrm{c} \mathrm{pH}=4.76$. When the ratio of gelatin/CMC was 9:1, the pH range for the formation of spherical microcapsules was 4.54 to 4.71 , and its particle size decreased while lowering the $\mathrm{pH}$ value 

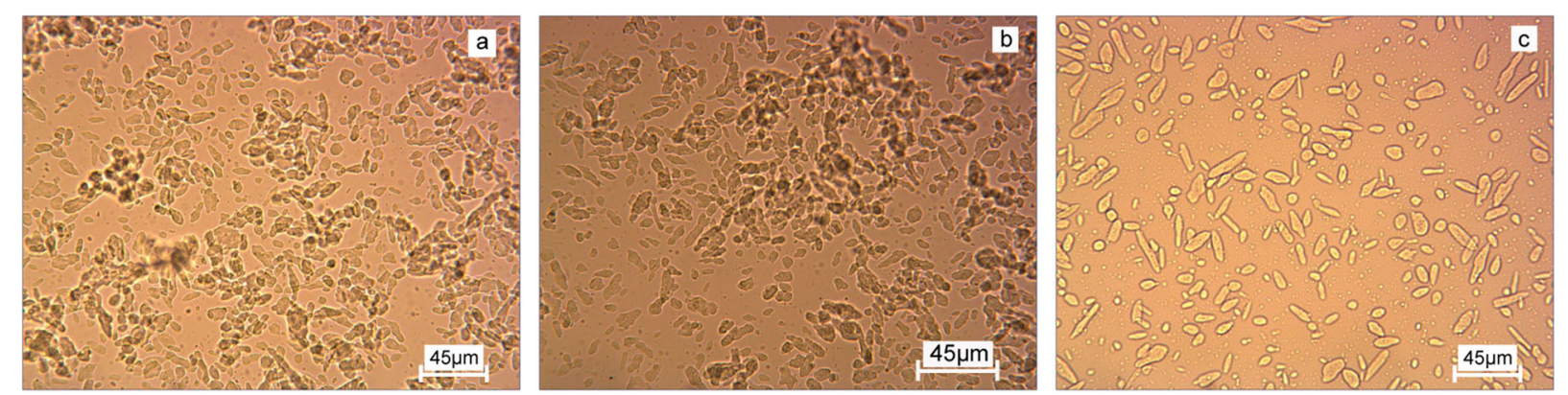

Fig. 5 The microcapsule morphology at different $\mathrm{pH}$ values with the gelatin/CMC ratio of 11: 1. a $\mathrm{pH}=4.69, \mathrm{~b} \mathrm{pH}=4.74, \mathrm{c} \mathrm{pH}=4.78$. When the ratio of gelatin/CMC was 11:1, the $\mathrm{pH}$ range of microcapsules for pellet formation was between 4.69 and 4.74

of the total charge of gelatin on the $\mathrm{pH}$ value, and the greatest was the influence on the complex coacervation.

\section{Determination of wall material concentration}

Figure 6 shows the effect of total wall material concentration on the encapsulation process. Spherical microcapsules appeared, when the wall material concentration was $0.5 \%$ (Fig. $7 \mathrm{a}$ ). However, many empty capsules were not embedded in the core material, because the lowest colloidal concentration in the solution resulted in poor emulsification performance and reduced the stability of the system. The emulsion droplets could easily aggregate to form larger microcapsules, and the density of virus was relatively small in the system. Therefore, many microcapsules were formed with extremely small particle size and empty capsules (without core material), which not only reduced the utilization rate of the wall material, but also the microcapsules with very small particle size eventually clogged the filter paper. Therefore, separation and subsequent operations could not be performed. When the wall material concentration was $1 \%$, the formed microcapsules exhibited uniform particle size and good morphology. When the wall material concentration was increased to 1.5 and $2 \%$, the amount of composite condensate, formed by $\mathrm{CMC}$ and gelatin, increased significantly. However, no uniform spherical microcapsule was formed, but huge strip-shaped condensates were produced. Therefore, when the wall material concentration was $1 \%$, the
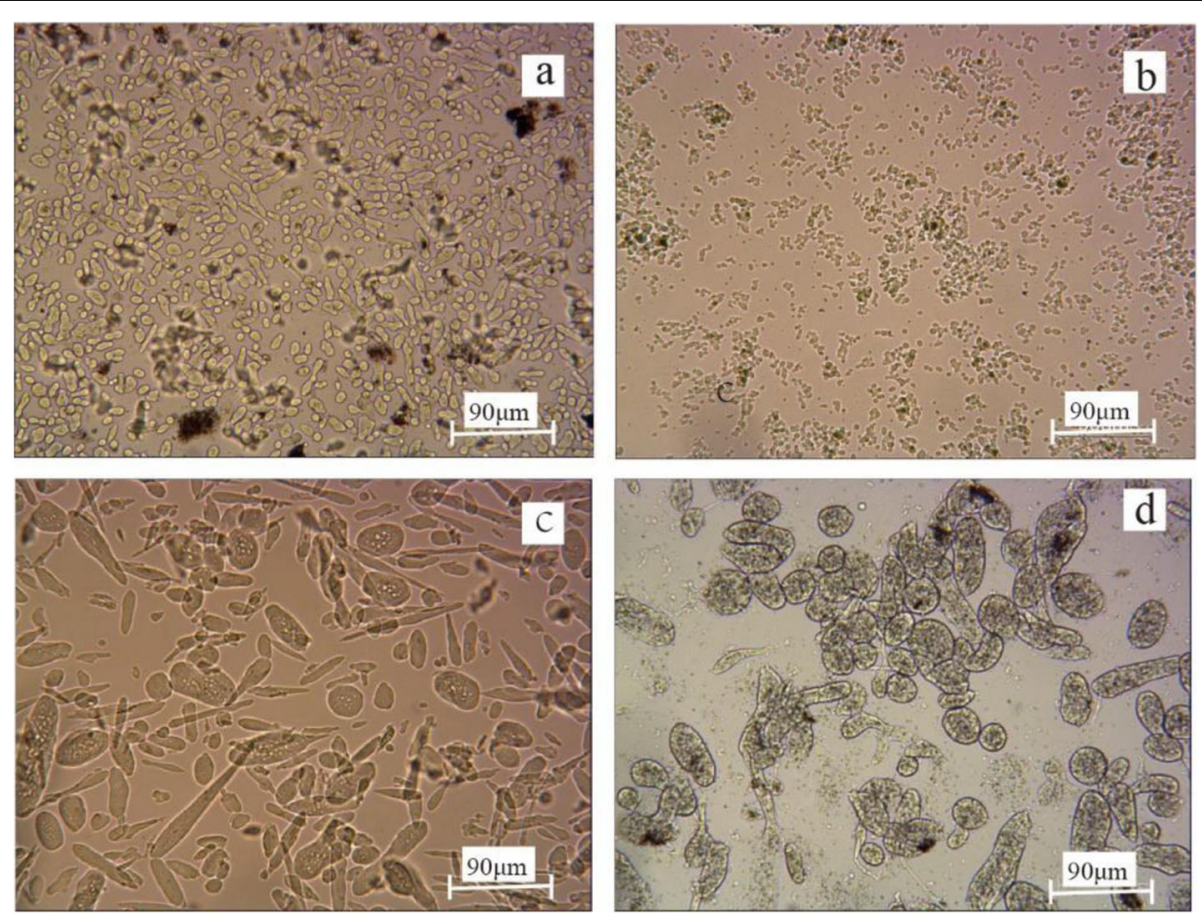

Fig. 6 The effect of wall material concentration on the morphology of composite condensate microcapsules. a Wall material concentration was $0.5 \%$. b Wall material concentration was $1 \%$. c Wall material concentration was $1.5 \%$. d Wall material concentration was $2 \%$ 

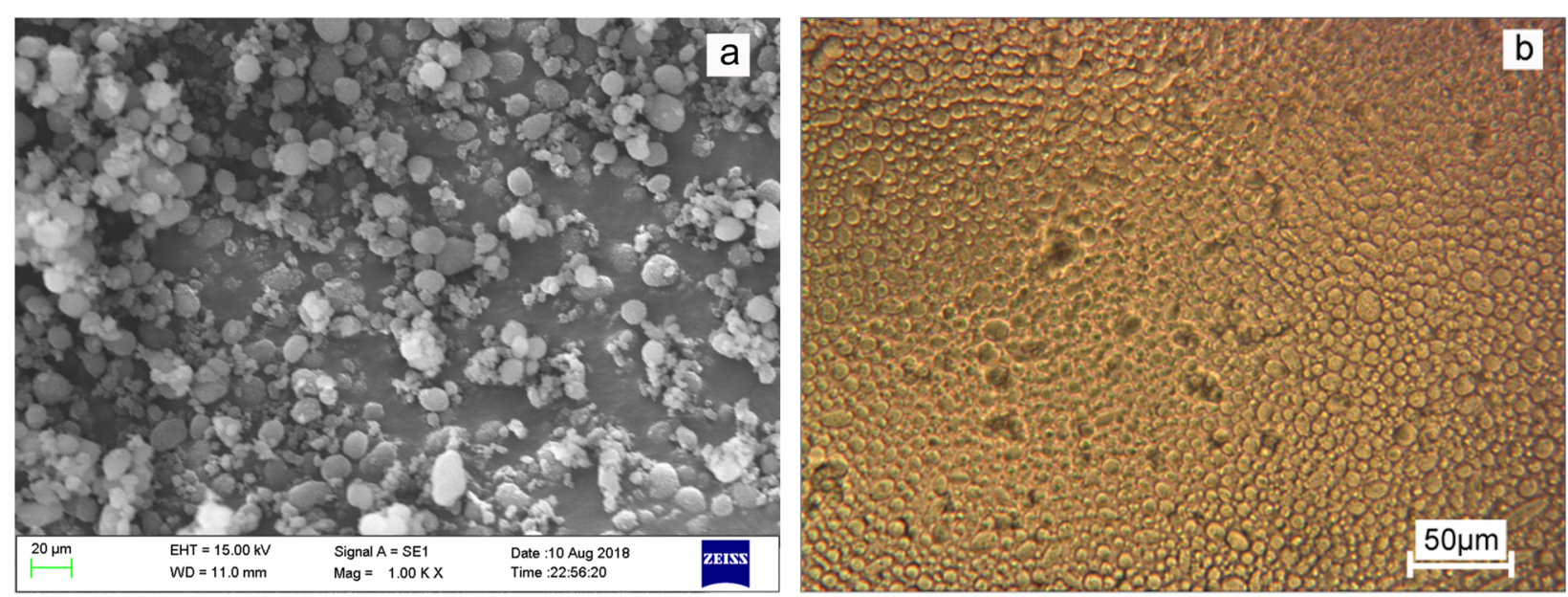

Fig. 7 Observation of microcapsule morphology. a Scanning electron micrograph of microcapsules. b Optical micrograph of microcapsules

optimal concentration of wall material to form microcapsules was $1 \%$.

\section{Analysis of morphology}

Figure 7 shows the scanning electron micrograph and optical micrograph of the virus microcapsules. Figure 7a represents a scanning electron micrograph of virus microcapsules, obtained by solidification and suction filtration, where the spherical microcapsules can be observed clearly; the size is relatively uniform; the surface is smooth and dense; and the microcapsules are adhered to each other, probably because the gelatin in the wet capsule has not been washed thoroughly. Figure $7 \mathrm{~b}$ represents an optical microscopic image of the virus microcapsule (wet capsules), where the spherical microcapsules with uniform particle size and good dispersion can be observed.

\section{Determination of the core-to-wall ratio}

Figure 8 shows that the core-to-wall ratio has not affected the particle size of the microcapsules, probably because the virus particles are smaller than the diameter of the microcapsules, and only a small number of viruses are embedded in a single microcapsule, and the particle size has been affected mainly by the ratio of gelatin/CMC. The core-to-wall ratio affected mainly the drug loading and embedding rate of the virus. Also, the drug-loading amount increased slightly with the

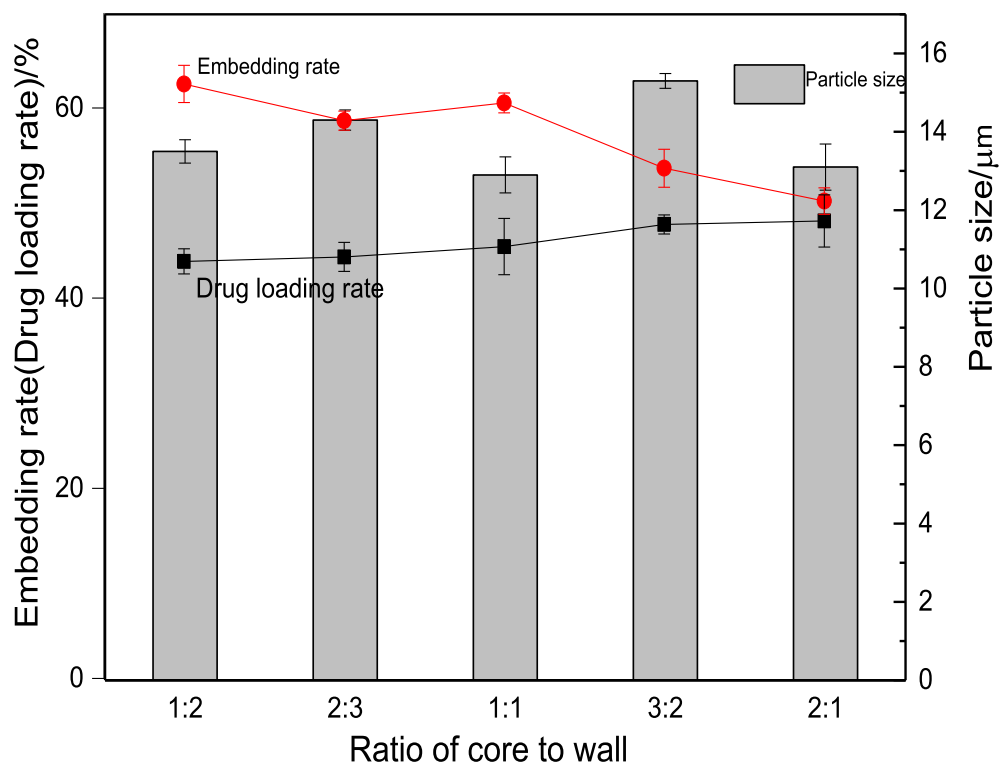

Fig. 8 Effect of core-to-wall ratio on microcapsule parameters 
Table 2 Cumulative mortality of 3rd instar larvae of Spodoptera litura infected with viruses at different concentrations

\begin{tabular}{lllll}
\hline Concentration (PIB/ml) & No. of Experimental insects & No. of larval Mortality & Mortality rate (\%) & Corrected mortality rate (\%) \\
\hline $7.75 \times 10^{6}$ & 60 & 58 & 97 & 97 \\
$7.75 \times 10^{5}$ & 60 & 54 & 90 & 90 \\
$7.75 \times 10^{4}$ & 60 & 30 & 50 & 50 \\
$7.75 \times 10^{3}$ & 60 & 10 & 17 & 17 \\
$7.75 \times 10^{2}$ & 60 & 0 & 0 & 0 \\
$\mathrm{CK}$ & 60 & 0 & 0 & \\
\hline
\end{tabular}

increase in the core-to-wall ratio, which tended to stabilize. When the core-to-wall ratio was increased from $1: 2$ to $1: 1$, the embedding ratio did not change much, and when the core-to-wall ratio was increased from $3: 2$ to $2: 1$, the embedding ratio decreased, probably because when the core material concentration in the reaction system was very high, excess core materials could not be embedded, and many unembedded viruses might attach to the surface of the microcapsules and cause the capsule wall to rupture. Therefore, the optimal core to wall ratio was 1:2.

\section{Determination of microencapsulated virus activity}

Tables 2, 3, and 4 show the results of virus activity tests. The corrected mortality rate of the microencapsulated virus at all concentrations was lower than that of the unembedded virus, and the $\mathrm{LC}_{50}$ value was $8.36 \times 10^{4}$ $\mathrm{PIB} / \mathrm{ml}$ that was calculated after $192 \mathrm{~h}$ of treatment, which was higher than that value of the unembedded virus $\left(1.90 \times 10^{4}\right)$, indicating that the activity of the microencapsulated virus was lower than that of the unembedded virus, probably because the virus was affected by factors, such as the temperature and $\mathrm{pH}$ of the reaction system, during the microencapsulation process, causing partial inactivation of the virus. Because the preparation conditions were relatively mild for the virus, the $\mathrm{LC}_{50}$ difference between the microencapsulated virus and the unembedded virus was within an order of magnitude. A substantial increase in the resistance of the microencapsulated virus to ultraviolet radiation in subsequent experiments suggested that the level of virus inactivation did not affect the application of microencapsulated virus.

\section{Effect of field exposure on microencapsulated S. litura nuclear polyhedrosis virus}

The effect of sunlight on the virus is a combination of ultraviolet rays, temperature, and other factors. From Fig. 9, it can be seen that the mortality rate of larvae infected with the virus powder after sunlight exposure from July 20 was only $10 \%$, and the pathogenicity rate of the microencapsulated virus after exposure to the field for 1 day was $53 \%$. After 4 days of exposure in the field, the pathogenicity rate of the virus powder has dropped to $0 \%$, that is, the virus had completely lost its activity. This may be due to the high outdoor ultraviolet intensity in Guangzhou in summer, which has a large inactivation effect on the virus. At the same time, the pathogenicity rate of the microencapsulated virus was $35 \%$ on the 4 th day, and it remained about $10 \%$ after the 10 th day. This is because the gelatin/CMC shell of the microcapsule can better protect the virus in the wild environment, reduce the influence of natural factors such as ultraviolet rays on the virus, and thus retain the activity of the virus.

\section{Discussion}

S. litura (Lepidoptera: Noctuidae) is a worldwide important agricultural pest, which causes severe damage to cotton, soybeans, tobacco, and other important cash crops (Ahmad et al., 2013), as well as causing severe damage to cash crop in Asia, Africa, South America, and some regions of Oceania (Shad et al., 2012; Tuan et al., 2014). In China, S. litura is the most prevalent in the southeast (Su et al., 2012).

The family Baculoviridae comprises 4 genera, of which viruses of the Alphabaculovirus genus (lepidopteran

Table 3 Cumulative mortality rate of 3rd instar larvae of Spodoptera litura infected at different concentrations of microencapsulated virus

\begin{tabular}{lllll}
\hline Concentrations (PIB/ml) & No. of Experimental insects & No. of larval Mortality & Mortality rate (\%) & Corrected mortality rate (\%) \\
\hline $7.75 \times 10^{\mathbf{6}}$ & 60 & 51 & 85 & 85 \\
$7.75 \times 10^{5}$ & 60 & 44 & 73 & 73 \\
$7.75 \times 10^{4}$ & 60 & 27 & 45 & 45 \\
$7.75 \times 10^{3}$ & 60 & 5 & 8 & 8 \\
$7.75 \times 10^{2}$ & 60 & 0 & 0 & 0 \\
$\mathrm{CK}$ & 60 & 0 & 0 & 0 \\
\hline
\end{tabular}


Table 4 Regression equation, correlation coefficient, and LC 50 between the viral tested concentrations and the mortality of 3rd instar larvae

\begin{tabular}{|c|c|c|c|c|c|}
\hline \multirow[t]{2}{*}{ Items } & \multirow[t]{2}{*}{ Regression equation } & \multirow{2}{*}{$\begin{array}{l}\text { Correlation } \\
\text { coefficient }\end{array}$} & \multirow{2}{*}{$\begin{array}{l}\text { LC50 } \\
\text { (PIB/ml) }\end{array}$} & \multicolumn{2}{|c|}{$95 \%$ confidence limit (PIB/ml) } \\
\hline & & & & Upper limit & Lower limit \\
\hline Virus & $Y=-2.9393+1.5215 x$ & 0.9381 & $1.65 \times 10^{5}$ & $1.20 \times 10^{5}$ & $2.28 \times 10^{5}$ \\
\hline Microencapsulated virus & $Y=-2.44+1.34 x$ & 0.9240 & $3.65 \times 10^{5}$ & $2.53 \times 10^{5}$ & $5.25 \times 10^{5}$ \\
\hline
\end{tabular}

nucleopolyhedroviruses, NPV) have shown considerable potential as bioinsecticides (Eberle et al., 2012). They are host-specific and have no adverse effect on natural enemies or other non-target insect populations, whereas the application of conventional insecticides reduces the abundance of beneficial agents (Rodgers 1993; Armenta et al., 2003).

Pest control efficacy in the field is often compromised because of the rapid loss of insecticidal activity resulting from exposure to sunlight (Wood and Granados 1991; Huber and Ludcke 1996). Therefore, the development of embedded virus particles has become the preferred delivery system to reduce the loss of activity due to solar radiation (Tamez et al., 2002). Behle et al., (2003) tested spray-dried AfMNPV formulations after storage for insecticidal activity based on bioassays with neonate Trichoplusia ni (Hübner). Experiments demonstrated that AfMNPV in lignin-based spray-dried formulations had a shelf-life of up to 3 months at $30{ }^{\circ} \mathrm{C}$ and up to 30 months at $4{ }^{\circ} \mathrm{C}$, and with longer residual insecticidal activity in the field compared to unformulated or a glycerin formulation. Camacho et al. (2015) improved virus survival in ultraviolet light by preparing microcapsules of the virus with Polyacrylic acid resin, but because of its emulsification, the cost of microencapsulation is too high due to the pollution of oil phase and the complicated impurity removal process.

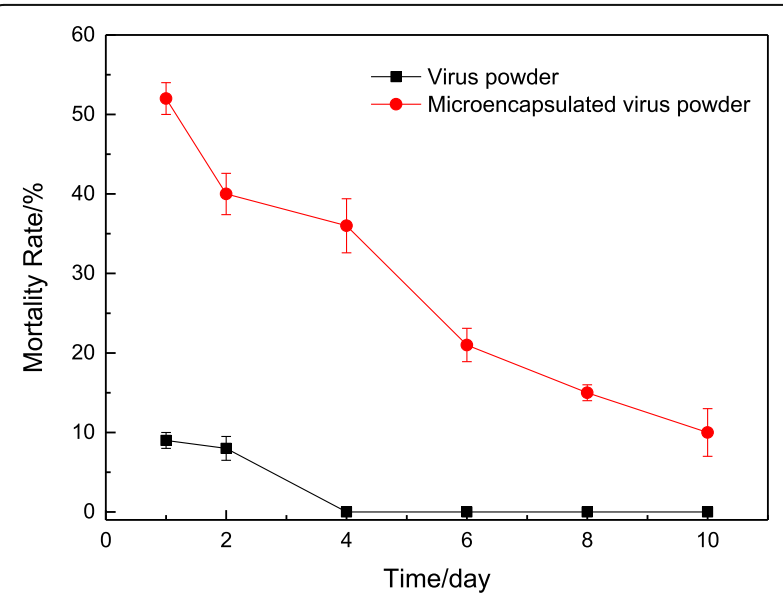

Fig. 9 Infection mortality of Spodoptera litura larvae after field exposure
For the sake of prolonging the activity of S. litura, microencapsulated NPV was prepared by complex coacervation method. Gelatin/gum Arabic (Yang et al., 2019; Shadel et al., 2018) is usually used to prepare the wall materials of microcapsules. However, gum Arabic is expensive and has poor stability, so CMC, which is cheap and stable, is chosen as the substitute of gum Arabic. The Wall Hardener is formaldehyde (Takenaka et al., 2010)

The wall of the microcapsule was solidified by the covalent bond between o-benzylic phenol and protein secondary amine, and the wall was denser and strongest. However, it can only react under strong alkali condition, and the virus activity will decrease rapidly under alkaline condition. For this reason, the tea polyphenol, which is more green and environmental friendly, is chosen as curing agent to form microcapsules with complete spherical shape, uniform particle size, and good dispersion.

In order to prolong the activity of S. litura, the optimum preparation conditions of microcapsules were selected for encapsulation of NPV. The virulence of microencapsulated virus was tested in laboratory and compared to that of unencapsulated virus. The results showed that the corrected mortality of microencapsulated virus was 2.21 times less than that of unencapsulated virus under the same concentration, but it can improve the tolerance of the virus in the field. Consequently, one way to increase baculovirus insecticidal activity is the synergistic combination with low concentrations of synthetic insecticides (Dáder et al., 2020).

Synergy is defined by the interaction of two or more pesticides to produce a combined mortality greater than the sum of their separate effects, which has been shown for azadirachtin and Helicoverpa armigera single nucleopolyhedrovirus (HearSNPV), Spodoptera frugiperda multiple nucleopolyhedrovirus (SfMNPV) and $S$. litura multiple nucleopolyhedrovirus (SpltMNPV) (Nathan et al., 2006; Zamora-Avilés et al., 2013), the organophosphate chlorpyrifos and S. litura granulovirus (SpltGV) (Subramanian et al., 2005), and the spinosynspinosad and Spodoptera littoralis nucleopolyhedrovirus (SpliNPV) and SfMNPV (Méndez et al., 2002; El-Helaly et al., 2015). The mortality of the Guatemalan moth Tecia solanivora (Povolný) (Lepidoptera: Gelechiidae) was high when granuloviruses isolated from Phthorimaea operculella (Zeller) 
(Lepidoptera: Gelechiidae) and T. solanivora were combined with the carbamate carbofuram or chlorpyrifos (Espinel et al., 2009).

The combination of baculoviruses and other pesticides in packages is undoubtedly preferable. It is worth noting that the main cause of death is through baculovirus or through the combination of insecticides to kill.

In a natural forest ecosystem, plant chemistries contribute to complex interactions depending on many parameters of the particular ecosystem, such as the density of oak trees in a forest (Elderd et al., 2013). Although comparatively less complex, reports of interactions among crop, pest, and pathogen vary for monoculture cropping systems. The susceptibility of Helicoverpa zea to Helicoverpa zea nucleopolyhedrovirus was found to be greater when fed on soybean rather than cotton; however, no specific plant chemistry was identified (Ali et al., 1998). In okra and tomato, induced plant defense chemistries are correlated with reduced baculovirus infection of the lepidopteron Heliothis virescens (Fabricius); however, induced systemic acquired resistance in cotton foliage had no effect on baculovirus infection of the lepidopteron $H$. armigera (Hübner) (Jeyarani et al., 2011).

Therefore, exploring the interaction among the host plant, beet armyworm, and microencapsulated beet armyworm nucleopolyhedrovirus is also one of the research focuses.

\section{Conclusions}

In this study, gelatin/CMC-S. litura nucleopolyhedrovirus microcapsules were prepared by the complex coacervation method using $S$. litura nucleopolyhedrovirus as the core material, gelatin, and CMC as the wall materials, and tea polyphenols as the curing agent. The capsule preparation process was simple and cost-effective. The optimal process parameters for the formation of microcapsules were gelatin/CMC ratio of 9:1, wall material concentration of $1 \%$, core wall ratio of $1: 2$, and curing time of $1 \mathrm{~h}$. The particle size of the prepared virus microcapsules was $13 \mu \mathrm{m}$, the drug loading was $43.87 \%$, the embedding rate was $62.53 \%$, and $\mathrm{LC}_{50}$ of the microencapsulated virus was $8.36 \times 10^{4}(\mathrm{PIB} / \mathrm{ml})$ after $192 \mathrm{~h}$ of treatment. The laboratory virulence test of the microencapsulated virus showed that its activity was by 2.21 times less than that of the untreated virus. Sunny and high-temperature weather conditions were not conducive to maintaining the stability of the virus. The activity of S. litura nuclear polyhedrosis virus under sunny and high-temperature weather conditions was lower than that under rainy weather conditions. The survival ability of microencapsulated S. litura nuclear polyhedrosis virus in the field environment was significantly higher than that of unembedded virus. Microencapsulation improved the tolerance of $S$. litura nuclear polyhedrosis virus to ultraviolet radiation.

\section{Abbreviations}

CMC: Carboxymethylcellulose; UV: Ultraviolet solar radiation; GpGv: Cydia pomonella granulovirus

\section{Acknowledgements \\ Authors would like to thank Jianmei Shen for data modeling (Zhongkai University of Agriculture and Engineering, Guangdong, China).}

\section{Authors' contributions}

$M L$ prepared the microcapsules and analyzed their surface morphology and field exposure data and was a major contributor to the manuscript. DZ analyzed the virulence assays. Surface potential of microcapsules was measured by $\mathrm{JL}$ and $\mathrm{CZ}$. XP and XZ were responsible for writing reviews and edits. All authors read and approved the final manuscript.

\section{Funding}

This research was funded by the Major Project of Collaborative Innovation of Industry, University and Research in Guangzhou Science and Technology Plan, grant number 201704020025 and 201704020018 , Innovation Team Project by the Department of Education of Guangdong Province

(2018KCXTD015) and Innovation Team of Modern Agricultural Industry Technology System of Guangdong Province (2019KJ140). Above funds provided fund for collecting samples and buying chemicals for experiments and supported experimental facilities to carry out experiments.

\section{Availability of data and materials}

All data generated or analyzed during this study are included in this published article.

\section{Declarations}

Ethics approval and consent to participate

This article does not contain any studies with human participants or animals performed by any of the authors. All participants have given oral informed consent.

\section{Consent for publication}

Not applicable

\section{Competing interests}

The authors declare no conflict of interest.

\section{Author details}

${ }^{1}$ College of Chemistry and Chemical Engineering, Zhongkai University of Agriculture and Engineering, Guangzhou 510225, China. ${ }^{2}$ Key Laboratory of Agricultural Green Fine Chemicals of Guangdong Higher Education Institution, Guangzhou 510225, China. ${ }^{3}$ Guangzhou Biological Control Station, Guangzhou 510460, China.

Received: 6 April 2021 Accepted: 26 June 2021

Published online: 14 July 2021

\footnotetext{
References

Ahmad M, Ghaffar A, Rafiq M (2013) Host plants of leaf worm, Spodoptera litura (Fabricius) (Lepidoptera: noctuidae) in Pakistan. Asian J Agric Biol 1:23-28

Ali Ml, Felton GW, Meade T, Young SY (1998) Influence of interspecific and intraspecific host plant variation on the susceptibility of heliothines to a baculovirus. Biol Control 12(1):42-49 https://doi.org/10.1006/bcon.1998.0619 Armenta R, Martínez AM, Chapman JW, Magallanes R, Goulson D, Caballero P, Cisneros J, Valle J, Castillejos V (2003) Impact of a nucleopolyhedrovirus bioinsecticide and selected synthetic insecticides on the abundance of insect natural enemies on maize in Southern Mexico. J Econ Entomol 96(3):649661. https://doi.org/10.1603/0022-0493-96.3.649

Arthurs SP, Lacey LA, Behle RW (2006) Evaluation of spray-dried lignin-based formulations and adjuvants as solar protectants for the granulovirus of the codling moth, Cydia pomonella (L). J Invertebr Pathol 93(2):88-95 https://doi. org/10.1016/j.jp.2006.04.008
} 
Balabanidou V, Grigoraki L, Vontas J (2018) Insect cuticle: a critical determinant of insecticide resistance. Curr Opin Insect Sci 27:68-74 https://doi.org/ 10.1016 / j.cois.2018.03.001

Behle RW, Patricia TG, Mcguire MR (2003) Field activity and storage stability of Anagrapha falcifera nucleopolyhedrovirus (AfMNPV) in spray-dried ligninbased formulations. J Econ Entomol 96(4):1066-1075 https://doi.org/10.1603/ 0022-0493-96.4.1066

Bilal M, lqbal HMN, Barceló D (2019) Persistence of pesticides-based contaminants in the environment and their effective degradation using laccase-assisted biocatalytic systems. Sci Total Environ 695:133896 https://doi. org/ 10.1016 / j.scitotenv.2019.133896

Camacho KJE, Gómez AMI, Villamizar RLF (2015) Microencapsulation of a Colombian Spodoptera frugiperda nucleopolyhedrovirus with Eudragit 5100 by spray drying. Braz Arch Biol Techn 58(3) https://doi.org/10.1590/S15168913201500453:468-476

Cory JS (2015) Insect virus transmission: different routes to persistence. Curr Opin Insect Sci 8:130-135 https://doi.org/10.1016/j.cois.2015.01.007

Dáder B, Aguirre E, Caballero P, Medina P (2020) Synergy of lepidopteran Nucleopolyhedroviruses AcMNPV and SpliNPV with insecticides. Insects 11(5): 316 https://doi.org/10.3390/insects11050316

Duhoranimana E, Yu J, Mukeshimana O, Habinshuti I, Karangwa E, Xu X, Muhoza B, Xia S, Zhang X (2018) Thermodynamic characterization of gelatin-sodium carboxymethyl cellulose complex coacervation encapsulating conjugated linoleic acid (CLA). Food Hydrocolloids 80(JUL.): 149-159. https://doi.org/. 80: 149-159. https://doi.org/10.1016/j.foodhyd.2018.02.011

Eberle KE, Jehle JA, Huber J (2012) Microbial control of crop pests using insect viruses. In Integrated Pest Management: Principles and Practice; Abrol DP, Shankar U (eds ) CAB International: Wallingford, UK, pp. 281-298.

Elderd BD, Rehill BJ, Haynes KJ, Dwyer G (2013) Induced plant defenses, hostpathogen interactions, and forest insect outbreaks. Proceedings of the National Academy of Sciences of the United States of America 110(37): 14978-14983 https://doi.org/10.1073/pnas.1300759110

El-Helaly A, El-bendary HM (2015) Field study to evaluate the joint action of certain insecticides, IGR's andbaculoviruses against Spodoptera littoralis (Bosid.). J Entomol Zool Stud 3:289-293

Espinel C, Gómez J, Villamizar L, Cotes AM, Léry X, Lópezferber M (2009) Biological activity and compatibility with chemical pesticides of a Colombian granulovirus isolated from Tecia solanivora. lobc/wprs Bulletin.

Finney DJ (1971) Probit analysis, 3rd edn. Cambridge University Press, Cambridge

Gomez EJ, Comunian TA, Montero P, Favaro TCS (2018) Physico-chemical properties, stability, and potential food applications of shrimp lipid extract encapsulated by complex coacervation. Food Bioprocess Technol 11:1-9 https://doi.org/ 10.1007 / s11947-018-2116-3

Huber J, Ludcke C (1996) UV-inactivation of baculo-virusis: The bisegmented survival curve. IOBC J Bull 19:253-256

Jeyarani S, Karuppuchamy P, Sathiah N (2011) Influence of Pseudomonas fluorescens-induced plant defenses on efficacy of nucleopolyhedrovirus of Helicoverpa armigera in okra and tomato. International Journal of Vegetable Science 17(3):283-295 https://doi.org/10.1080/19315260.2011.553122

Jones OG, Lesmes U, Dubin P, Mcclements DJ (2009) Effect of polysaccharide charge on formation and properties of biopolymer nanoparticles created by heat treatment of $\beta$-lactoglobulin-pectin complexes. Food Hydrocolloids 24 : 374-383 https://doi.org/ 10.1016 / j.foodhyd.2009.11.003

Méndez WA, Valle J, Ibarra JE, Cisneros J, Penagos DI, Williams T (2002) Spinosad and nucleopolyhedrovirus mixtures for control of Spodoptera frugiperda (Lepidoptera: Noctuidae) in maize. Biol Control 25(2): https://doi.org/ 195-2 06. 10.1016/S1049-9644(02)00058-0, 25, 2, 195, 206.

Nathan SS, Kalaivani K (2006) Combined effects of azadirachtin and nucleopolyhedrovirus (SpltNPV) on Spodoptera litura Fabricius (Lepidoptera: Noctuidae) larvae. Biol Control 39(1):96-104 https://doi.org/10.1016/j. biocontrol.2006.06.013

Rodgers PB (1993) Potential of biopesticides in agriculture. Pestic Sci 39(2):117129. https://doi.org/10.1002/ps.2780390205

Sarika PR, Anupama JNR, Nirmala R (2015) Cationized gelatin/gum arabic polyelectrolyte complex: Study of electrostatic interactions. Food Hydrocolloids 49:176-182 https://doi.org/10.1016/j.foodhyd.2015.02.039

Serge L, Sylvie L, Paul P (2006) Emulsion-stabilizing properties of chitosan in the presence of whey protein isolate: Effect of the mixture ratio, ionic strength and pH. Carbohydr Polym 65:479-487 https://doi.org/10.1016 / j.carbpol.2 006.02.024
Shad SA, Sayyed AH, Fazal S, Saleem MA, Zaka SM, Ali M (2012) Field evolved resistance to carbamates, organophosphates, pyrethroids, and new chemistry insecticides in spodoptera litura fab. (lepidoptera: noctuidae). J Pest Sci 85(1): 153-162 https://doi.org/10.1007/s10340-011-0404-z

Shaddel, Rezvan, Hesari, Javad, Azadmard D, Sodei, Hamishehkar H, Fathi AB, Qing RH (2018) Use of gelatin and gum Arabic for encapsulation of black raspberry anthocyanins by complex coacervation. Int J Biol Macromol 107. https://doi.org/10.1016/j.ijbiomac.2017.10.044.

Simon O, Williams T, Lopez-Ferber M, Caballero P (2004) Genetic structure of a spodoptera frugiperda nucleopolyhedrovirus population: high prevalence of deletion genotypes. Applied \& Environmental Microbiology 70(9):5579. https://doi.org/10.1128/AEM.70.9.5579-5588.2004

Su J, Lai T, Jia L (2012) Susceptibility of field populations of spodoptera litura (fabricius) (lepidoptera: noctuidae) in china to chlorantraniliprole and the activities of detoxification enzymes. Crop Prot 42: 217-222. https://doi.org/ 10.1016/j.cropro.2012.06.012.

Subramanian S, Rabindra RJ, Palaniswamy S, Sathiah N, Rajasekaran B (2005) Impact of granulovirus infection on susceptibility of Spodoptera litura to insecticides. Biol Control 33(2):165-172. https://doi.org/10.1016/j.biocontrol.2 005.01.007

Takenaka H, Kawashima Y, Lin SY (2010) Micromeritic properties of sulfamethoxazole microcapsules prepared by gelatin-acacia coacervation. J Pharm Sci 69(5):513-516 https://doi.org/10.1002/jps.2600690509

Tamez GP, Mcguire MR, Behle RW (2002) Storage stability of Anagrapha falcifera nucleopolyhedrovirus in spray-dried formulations. J Invertebr Pathol 79(1):716 https://doi.org/10.1016/S0022-2011(02)00005-8

Tuan SJ, Lee CC, Chi H (2014) Population and damage projection of spodopteralitura (f.) on peanuts (arachishypogaea l.) under different conditions using the age-stage, two-sex life table. Pest Manag Sci 70(5):805$813 \mathrm{https} / / /$ doi.org/10.1002/ps.3618

Villamizar L, Espinel C, Cotes AM (2009) Efecto de la radiación ultravioleta sobre la actividad insecticida de un nucleopoliedrovirus de spodoptera frugiperda (lepidoptera: noctuidae). Rev Colomb Entomol 35(2):116-121

Wood HA, Granados RR (1991) Genetically engineered baculoviruses as agents for pest control. Annu Rev of Microbiol 45(1):69-87 https://doi.org/10.1146/a nnurev.mi.45.100191.000441

Xing LP, Feng SD, Xiao HW (2019) Progress of the discovery, application, and control technologies of chemical pesticides in China. J Inter Agric 18:840853 https://doi.org/10.1016/S2095-3119(18)61929-X

Yan GY, Li CY, Sun J, Yang QZ (2020) Pang Xuelian, Zhang Baohua. Application of polydopamine/sodium alginate in insect virus preparations. Fine Chemicals 37(08):1684-1688

Yang L, Mengqi L, Xiaoyu D, Feng C, Jianhui P, Xiaojie C, Hongjun L, Tianhong L, Ying W, Xiguang C (2019) Development of alginate hydrogel/gum arabic/ gelatin based composite capsules and their application as oral delivery carriers for antioxidant. Inter J Biol Macromol 132:1090-1097 https://doi.org/1 0.1016/j.jijbiomac.2019.03.103

Zamora-Avilés N, Alonso-Vargas J, Pineda S, Isaac-Figueroa J, Lobit P, MartínezCastillo AM (2013) Effects of a nucleopolyhedrovirus in mixtures with azadirachtin on Spodoptera frugiperda (J. E. Smith) (Lepidoptera: Noctuidae) larvae and viral occlusion body production. Biocontrol Sci Techn 23(5):521534 https://doi.org/10.1080/09583157.2013.788133

\section{Publisher's Note}

Springer Nature remains neutral with regard to jurisdictional claims in published maps and institutional affiliations. 